\title{
Embryonic Urogenital System
}

National Cancer Institute

\section{Source}

National Cancer Institute. Embryonic Urogenital System. NCI Thesaurus. Code C34059.

The development of the organs of both the urinary and reproductive systems from the intermediate mesoderm. 